\title{
BMJ Open Binge drinking and associated factors among school students: a cross-sectional study in Zhejiang Province, China
}

\author{
Hao Wang, ${ }^{1}$ Ruying Hu, ${ }^{1}$ Jieming Zhong, ${ }^{1}$ Huaidong Du, ${ }^{2,3}$ Bragg Fiona, ${ }^{2}$ \\ Meng Wang, ${ }^{1}$ Min $\mathrm{Yu}^{1}$
}

To cite: Wang H, Hu R, Zhong J, et al. Binge drinking and associated factors among school students: a crosssectional study in Zhejiang Province, China. BMJ Open 2018;8:e021077. doi:10.1136/ bmjopen-2017-021077

- Prepublication history for this paper is available online. To view these files, please visit the journal online (http://dx.doi org/10.1136/bmjopen-2017021077).

Received 12 December 2017 Revised 27 February 2018 Accepted 7 March 2018
Check for updates

${ }^{1}$ Department of NCDs Control and Prevention, Zhejiang Provincial Center for Diseases Control and Prevention, Hangzhou, China

${ }^{2}$ Clinical Trial Service Unit \& Epidemiological Studies Unit (CTSU), Nuffield Department of Population Health, University of Oxford, Oxford, UK

${ }^{3}$ Medical Research Council

Population Health Research

Unit, Nuffield Department of

Population Health, University of Oxford, Oxford, UK

Correspondence to

Professor Min Yu;

myu@cdc.zj.cn

\section{ABSTRACT}

Objective To investigate the prevalence and correlating factors of binge drinking among middle and high school students in Zhejiang Province, China.

Methods We performed a cross-sectional study using data from a school-based survey. A total of 23543 (response rate $=97.5 \%$ ) eligible adolescents from 442 different schools (including middle schools, academic high schools and vocational high schools) were asked to fill in an anonymous self-administered behaviour questionnaire between April and May 2017. Multivariable logistic regression models were used to examine the associations of sociodemographic and behavioural factors with binge drinking.

Results The mean (SD) age of participants was 15.6 (1.7) years and $51.3 \%$ were boys. The proportions of students from middle schools, academic high schools and vocational high schools were $51.9 \%, 27.5 \%$ and $20.6 \%$, respectively. In total, $22.8 \%$ (95\% Cl 21.6 to 23.9 ) of students reported drinking alcohol in the past 30 days and $9.2 \%$ (95\% Cl 8.5 to 10.0) of students reported binge drinking (defined as drinking four or more alcoholic drinks in 1-2 hours period among girls and five or more alcoholic drinks among boys) during the past month. The prevalence of binge drinking was highest among vocational high school students $(17.9 \%$ vs $6.3 \%$ and $7.7 \%$ among middle school and academic high school students, respectively). Older age, studying at high school, poor academic performance, higher levels of physical activity, excessive screen-time, Ioneliness, insomnia, previous suicide attempt, cigarette smoking, fighting, being bullied and sexual experience were found to be positively associated with adolescent binge drinking.

Conclusions Binge drinking is common among middle and high school students in Zhejiang, China. Efforts to prevent binge drinking may need to address a cluster of sociodemographic and behavioural factors. Our findings provide information to enable healthcare providers to identify students at high-risk of binge drinking and to inform planning of intervention measures for at-risk students.

\section{INTRODUCTION}

Alcohol consumption has been identified as an important risk factor for chronic disease and injury. ${ }^{1}$ Disability-adjusted life-years attributable to alcohol consumption have

\section{Strengths and limitations of this study}

- This is a school-based study with a relatively large sample size, a high response rate and a study population which is representative of Provincial China.

- The study questionnaire includes a wide range of factors, which might help us better understand how to prevent adolescent binge drinking.

- The cross-sectional study design prevents establishment of causal relationships between sociodemographic or behavioural factors and binge drinking.

- Only students attending schools participated in the survey. Students who have been expelled or suspended from school, or who stopped attending, may be more likely to binge drink, and the overall prevalence of binge drinking in our current study might therefore represent an underestimate of the true prevalence.

increased by $>25 \%$ between 1990 and 2016 , accounting for an estimated 99.2 million worldwide. In 2016, alcohol consumption was responsible for $>2.8$ million deaths worldwide, including approximately 0.7 million in China. ${ }^{2}$ Many studies have clearly demonstrated that alcohol misuse among adolescents is associated with motor vehicle collisions, ${ }^{3}$ violence and crime, ${ }^{45}$ mental health disorders and higher risk of suicide. ${ }^{6-8}$ Moreover, alcohol use during early adolescence is a risk factor for later alcohol dependence. ${ }^{9-11}$

Binge drinking is defined as episodic excessive drinking. Prevalence of binge drinking among adolescents varies between countries, and is estimated to be $8 \%$ in Iceland and $56 \%$ in Denmark. ${ }^{12}$ Among 25 European countries, prevalence of binge drinking among adolescents rose from $36 \%$ in 1995 to $42 \%$ in 2007 , and then declined to $35 \%$ in 2015 . $^{12}$ In the USA, the prevalence declined from $31.3 \%$ in 1991 to $17.7 \%$ in $2015 .{ }^{13}$ In Asia, the prevalence of heavy episodic drinking (ie, binge drinking) among grade 7-12 students was $10.3 \%$ in Korea, ${ }^{14}$ while $21.2 \%$ of students, with mean age 14.7 years, reported 
drinking alcohol in the past 30 days and $7.1 \%$ reported binge drinking in Hong Kong. ${ }^{15}$ In mainland China, a study of 7344 middle school students conducted in four cities (Beijing, Hangzhou, Wuhan, Urumchi) found that the prevalence of current drinking was $14.4 \%$, and $9.9 \%$ of students had experienced drunkenness, with significant regional differences. ${ }^{16}$ In another study, conducted in 2004 and including 54040 students in grades 7-12 from 18 Provincial capitals in China, 25.2\% of students reported consuming at least one alcoholic drink and $10.3 \%$ reported at least one episode of binge drinking during the 30 days prior to being surveyed. ${ }^{17}$ A more recent study, surveying 13811 high school students from Beijing, Shanghai and Guangzhou in 2013, found the prevalence of binge drinking was $4.8 \%,{ }^{18}$ although not all school grades were included, likely resulting in underestimation of the true prevalence.

Parental alcohol-related practices have been shown to be important risk factors for adolescent drinking. ${ }^{19}$ In traditional Chinese culture, alcohol drinking is both a normal part of the daily diet, especially in rural areas, and an important part of rituals, business occasions, festivals and special events. Moderate drinking on important occasions is encouraged for adults, ${ }^{20}$ and children may be given small amounts of alcoholic beverages by parents or grandparents, especially grandfathers. ${ }^{18}$ Some previous surveys have found that nearly half of senior high schools students in China have drunk at home with their parents or outside the home with their peers. ${ }^{21} 22$

Previous studies have found some inconsistencies in sociodemographic patterns of adolescent binge drinking. For instance, Miller $e t a l^{23}$ reported that binge drinking prevalence was similar among high school boys and girls in the USA, while boys in Hong Kong had higher prevalence of binge drinking than girls. ${ }^{15}$ Sokol-Katz et $a l^{24}$ reported that family structure was not significantly related to behaviours such as alcohol, cigarette and drug use among middle school students in Florida, after controlling for gender and race/ethnicity, while growing up in a non-intact family was associated with substance use among Chinese adolescents in Hong Kong. ${ }^{25}$

Zhejiang Province, in the east of China, has a population of 56 million. It has experienced rapid economic development in the past 30 years, which has been associated with increased exposure of adolescents in Zhejiang to western culture. As a result of this, patterns of alcohol use in this area might differ from those in other regions of China. The current study was designed with the aim of examining the prevalence of binge drinking and its correlating factors among students in Zhejiang Province.

\section{METHODS}

\section{Survey design and participants}

The survey used a three-stage sampling design. In stage 1,30 counties, including 12 urban areas and 18 rural areas, were sampled randomly from all 90 counties (31 urban and 59 rural) of Zhejiang Province according to socioeconomic status. In stage 2, 10 classes of middle school, 5 classes of academic high school and 5 classes of vocational high school were selected randomly within each chosen counties, respectively. In stage 3 , all students in the chosen classes were invited to participate in the study. In China, after 6 years of primary school education, children usually attend middle school (ie, junior high school) for 3years (grades 7-9). After graduation from middle schools, they enter high school (ie, senior high school, including academic high schools and vocational high schools) for a further 3 years (grades 10-12). The survey questionnaire was modelled from existing surveys including the Youth Risk Behaviour Survey, conducted by the Centers for Disease Control and Prevention (CDC), ${ }^{26}$ and the international Global School-based Student Health Survey, supported by WHO. ${ }^{27}$ Survey questions addressed demographic characteristics (including age, gender, parental educational level, parental marital status, number of siblings), tobacco and alcohol use, physical activity, violence, injuries, suicidal behaviours and sexual behaviours. The survey was conducted between April and May 2017. Participants completed the anonymous, self-administrated questionnaire in the classroom.

\section{Sample size calculation}

The sample size was calculated by using the formula: $\mathrm{n}=\operatorname{deff} \times \mu^{2} \times \mathrm{P} \times(1-\mathrm{P}) / \mathrm{d}^{2}$. Means and $95 \%$ CI (2-sided for $\mu=1.96$ ) were determined; the prevalence of binge drinking (10\%) obtained in the China was used as a measure of probability $(\mathrm{P}) ;{ }^{17}$ the design effect (deff) value was set at 3 and the relative error was: $d=r \times 1 \%$, $\mathrm{r}=15 \%$. Based on these parameters, the sample size for each stratum was estimated to be 4610 subjects. Because there were four strata (areas: urban and rural; sex: boy and girl), and assuming a potential non-response rate of $20 \%$, the final sample size was calculated as 23050 .

\section{Patient and public involvement}

Study participants were healthy students and no patients were involved in the study. Students and their parents were not involved in the design and conduct of study. Due to an anonymous survey, our findings will be disseminated to Department of Health and Department of Education, not directly to participating students.

\section{Measures}

\section{Outcome variables}

For the purposes of this study, alcoholic drinks include beer, wine, wine coolers, rice wine and liquor such as Chinese liquor, rum, gin, vodka or whiskey. Current drinking was assessed through the question: "During the past 30 days, on how many days did you have at least one drink of alcohol?" Answer options include: '0 days', '1-2 days', '3-5 days', '6-9 days', '10-19 days', '20-29 days' and ' 30 days'. Participants were considered as current drinkers if they reported drinking alcohol on at least 1-2 days during the past 30 days. Binge drinking was assessed by the question: "During the past 30 days, on how many 
days did you have 4 or more drinks of alcohol (if you are girl) or 5 or more drinks of alcohol (if you are boy) during a period of 1 to 2 hours?" 28 Answer options include: ' 0 days', ' 1 day', ' 2 days', '3-5 days', '6-9 days', '10-19 days', ' $\geq 20$ days'. Participants were defined as binge drinkers if they answered at least 1 day.

\section{Main covariates}

Physical activity was assessed by the question: "During the past 7 days, on how many days were you physically active for a total of at least $60 \mathrm{~min}$ per day?" Answer options included: 'none', ' 1 day', '2 days', '3 days', '4 days', '5 days', ' 6 days' and ' 7 days', and these were further categorised into four groups: 'none', '1-2 days/week', '3-5 days/week' and '6-7 days/week'. Current smoking was assessed by the question: "During the past 30 days, on how many days did you smoke cigarettes?" Answer options included: 'none', '1-2 days', '3-5 days', '6-9 days', '10-19 days', '20-29 days' and 'all 30 days'. Current smoking was defined as smoking cigarettes on at least 1-2 days in the past 30 days. Screen-time was estimated through the question: "On an average school day, how many hours do you play video or computer games or use a computer for something that is not school work?" Answer options included: 'none', '<1 hour/day', '1 hour/day', '2 hours/ day', '3 hours/day', '4 hours/day', ' $\geq 5$ hours/day', and these answers were further categorised into four groups: 'none', '<1 hour/day', '1-4 hours/day', ' $\geq 4$ hours/day'. Suicidal attempt was assessed using the question: "During the past 12 months, how many times did you actually attempt suicide?" Response options included: 'none', ' 1 time', '2-3 times', '4-5 times', ' 6 or more times', and suicide attempt was defined as at least once in the past 12 months. Fighting was assessed by the question: "During the past 12 months, how many times were you in a physical fight?" Answer options included: 'none', '1 time', '2-3 times', '4-5 times', '6-7 times', '8-9 times', '10-11 times', '12 or more times', and fighting was defined as at least once in the past 12 months. Being bullied was assessed by the question: "During the past 12 months, how many times has someone threatened or injured you with a weapon such as a gun, knife or club on school property?" Answer options included: 'none', '1 time', '2-3 times', '4-5 times', '6-7 times', '8-9 times', '10-11 times', '12 or more times'. Being bullied was defined as being threatened or injured by someone at least once in the past 12 months. More detailed information on covariates is provided in table 1 .

\section{Quality control}

The survey was conducted by trained surveyors from the local CDC. In order to improve response rate, every recruited student was given a pencil box as a gift, and the survey was anonymous.

\section{Ethics statement}

Written informed consent was obtained from all participants and their guardians before the survey.
Table 1 Questions comprising variables included in the survey

\begin{tabular}{ll}
\hline Variables & Questions and options \\
\hline Parental & What is the highest level of education your \\
education & father/mother has obtained? (Answer options: \\
level & $\begin{array}{l}\text { primary school or below, middle school, high } \\
\text { school, college or university, master graduates } \\
\end{array}$ \\
& or above, unknown)
\end{tabular}

Parental What is your parents' current marital status? marital (Answer options: married, divorced, widowed, status separated)

Siblings Are you the only son/daughter of your parent?(Answer options: yes, no)

Physical During the past 7 days, on how many days activity were you physically active for a total of at least 60 min per day? (Answer options: none, 1 day, 2 days, 3 days, 4 days, 5 days, 6 days, 7 days)

\begin{tabular}{|c|c|}
\hline $\begin{array}{l}\text { Academic } \\
\text { performance }\end{array}$ & $\begin{array}{l}\text { How would you describe your grades in } \\
\text { class? (Answer options: excellent, middle, } \\
\text { poor) }\end{array}$ \\
\hline Screen-time & $\begin{array}{l}\text { On an average school day, how many hours } \\
\text { do you play video or computer games or use } \\
\text { a computer for something that is not school } \\
\text { work? (Answer options: none, }<1 \text { hour/day, } \\
1 \text { hour/day, } 2 \text { hours/day, } 3 \text { hours/day, } 4 \text { hours/ } \\
\text { day, } \geq 5 \text { hours/day) }\end{array}$ \\
\hline
\end{tabular}

Loneliness During the past 12 months, did you ever feel lonely? (Answer options: never, occasional, sometimes, often, always)

Insomnia During the past 12 months, have you ever felt worried about something such that you cannot fall asleep? (Answer options: never, occasional, sometimes, often, always)

$\begin{array}{ll}\begin{array}{l}\text { Suicidal } \\ \text { attempt }\end{array} & \begin{array}{l}\text { During the past } 12 \text { months, how many times } \\ \text { did you actually attempt suicide? (Answer } \\ \text { options: none, 1 time, 2-3 times, 4-5 times, } 6 \\ \text { or more times) }\end{array} \\ \begin{array}{l}\text { Current } \\ \text { smoking }\end{array} & \begin{array}{l}\text { During the past } 30 \text { days, on how many days } \\ \text { did you smoke cigarettes? (Answer options: } \\ \text { none, 1-2 days, 3-5 days, 6-9 days, 10- } \\ \text { 19days, 20-29 days and all 30 days) }\end{array}\end{array}$

Fighting During the past 12 months, how many times were you in a physical fight? (Answer options: none, 1 time, 2-3 times, 4-5 times, 6-7 times, 8-9 times, 10-11 times, 12 or more times)

Being bullied During the past 12 months, how many times has someone threatened or injured you with a weapon such as a gun, knife or club on school property? (Answer options: none, 1 time, 2-3 times, 4-5 times, 6-7 times, 8-9 times, 10-11 times, 12 or more times)

\begin{tabular}{ll}
$\begin{array}{l}\text { Sexual } \\
\text { experience }\end{array}$ & Have you ever had sexual intercourse? \\
\hline
\end{tabular}

\section{Statistical analysis}

All analyses were performed using SAS software V.9.3. A weighting factor was applied to each student record to 
adjust for non-response and for the varying probabilities of selection. The weight used for estimation in this survey is given by: $\mathrm{W}=\mathrm{W} 1 \times \mathrm{W} 2 \times \mathrm{f} 1 \times \mathrm{f} 2$. $\mathrm{W} 1=$ the inverse of the probability of selecting the county; $\mathrm{W} 2=$ the inverse of the probability of selecting the classroom within the county; fl=a student-level non-response adjustment factor calculated by class; $\mathrm{f} 2=$ a poststratification adjustment factor calculated by grade. ${ }^{29}$ Continuous variables were given as the mean $\pm \mathrm{SD}$. The prevalence of current drinking and binge drinking was given as per cent and 95\% CI. Weighted prevalence was calculated using the PROC SURVEYFREQ procedure and its difference between groups was compared using Rao-Scott $\mathrm{X}^{2}$ test. To assess the associations between each correlating factor and binge drinking, univariate and multivariable logistic regression analyses were performed using the PROC SURVEYLOGISTC procedure, to take into account the complex survey sampling methods. We first determined which factors were associated with binge drinking in univariate analyses $(\mathrm{P}<0.05)$, and variables significant in the univariate analyses were entered in a multivariable logistic regression model. All statistical tests were two tailed, and $\mathrm{P}$ values $<0.05$ were considered to be statistically significant.

\section{RESULTS}

\section{Descriptive statistics}

A total of 24157 students were invited to participate. Due to missing or incomplete questionnaires and refusal to participate, 23543 eligible participants (response rate $97.5 \%)$ were included in the current analyses. Twelve thousand sixty-eight $(51.3 \%)$ participants were boys and, overall, mean age was 15.6 years. Twelve thousand two hundred seven $(51.9 \%)$ participants were middle school students, $6477(27.5 \%)$ were academic high school students and $4859(20.6 \%)$ came from vocational high schools.

The percentage of students that came from non-intact families was 9.9 (table 2); $11.4 \%$ of students' paternal educational level was college or above; $17.7 \%$ of students' maternal educational level was high school; $54.8 \%$ of students had siblings; $22.5 \%$ of students reported having excellent academic performance; 20.7\% of students reported being physically active $6-7$ days per week; $21.5 \%$ of students reported $>4$ hours screen-time per day; $64.1 \%$ of students reported never or occasionally feeling lonely during the past 12 months; $4.7 \%$ of students reported being often or always worried about something such that they could not sleep during the past 12 months; $5.5 \%$ of students reported smoking cigarettes during the past 30 days; $15.6 \%$ of students reported engaging in a physical fight and $13.2 \%$ reported being bullied during the past 12 months and $3.9 \%$ of students reported ever having sexual intercourse.

\section{The prevalence of current drinking and binge drinking}

As shown in table 3 , the prevalence of current drinking was $22.8 \%$ (95\% CI 21.6 to 23.9), higher among boys than girls
Table 2 Characteristics of adolescents from Zhejiang $(\mathrm{n}=23543)$

\begin{tabular}{llll}
\hline Characteristics & Total & Boys & Girls \\
\hline Age range (years) & & & \\
$\leq 13$ & $5159(20.9)$ & $2689(21.1)$ & $2470(20.8)$ \\
14 & $4300(17.8)$ & $2192(17.7)$ & $2108(17.8)$ \\
15 & $3730(16.5)$ & $1905(16.5)$ & $1825(16.6)$ \\
$\geq 16$ & $10354(44.8)$ & $5282(44.7)$ & $5072(44.8)$ \\
\hline
\end{tabular}

Area

\begin{tabular}{lccc} 
Urban & $9022(31.8)$ & $4544(31.8)$ & $4478(31.9)$ \\
\hline Rural & $14521(68.2)$ & $7524(68.2)$ & $6997(68.1)$ \\
\hline $\begin{array}{l}\text { Types of school } \\
\text { Middle school }\end{array}$ & $12207(51.8)$ & $6364(52.4)$ & $5843(51.0)$ \\
\hline $\begin{array}{l}\text { Academic high school } \\
\text { Vocational high school }\end{array}$ & $4857(26.1)$ & $3223(25.1)$ & $3254(27.3)$ \\
\hline $\begin{array}{l}\text { Parental marital status } \\
\text { Married }\end{array}$ & $2481(22.5)$ & $2378(21.7)$ \\
\hline Others & $21151(90.1)$ & $10924(90.9)$ & $10227(89.2)$ \\
\hline
\end{tabular}

Paternal education level

\begin{tabular}{|cccc|}
\hline Middle or below & $13568(60.0)$ & $6908(59.5)$ & $6660(60.5)$ \\
\hline High school & $5100(20.8)$ & $2628(20.8)$ & $2472(20.7)$ \\
\hline College or above & $3129(11.4)$ & $1575(11.2)$ & $1554(11.7)$ \\
\hline Unknown & $1746(7.8)$ & $957(8.5)$ & $789(7.1)$ \\
\hline $\begin{array}{l}\text { Maternal education level } \\
\text { Middle or below }\end{array}$ & $14530(63.9)$ & $7292(62.5)$ & $7238(65.5)$ \\
\hline High school & $4363(17.7)$ & $2271(18.0)$ & $2092(17.3)$ \\
\hline College or above & $2736(10.0)$ & $1392(9.8)$ & $1344(10.2)$ \\
\hline Unknown & $1914(8.4)$ & $1113(9.7)$ & $801(7.0)$ \\
\hline
\end{tabular}

Having siblings

\begin{tabular}{|cccc}
\hline Yes & $12137(54.8)$ & $5263(46.6)$ & $6874(63.8)$ \\
\hline No & $11406(45.2)$ & $6805(53.4)$ & $4601(36.2)$ \\
\hline Academic performance & & & \\
\hline Excellent & $5448(22.5)$ & $2731(21.7)$ & $2717(23.3)$ \\
\hline Middle & $11765(50.5)$ & $5727(48.1)$ & $6038(53.1)$ \\
\hline Bad & $6330(27.0)$ & $3610(30.2)$ & $2720(23.6)$ \\
\hline Physical activity (days/week) & & & \\
\hline 0 & $4883(21.5)$ & $2079(18.1)$ & $2804(25.2)$ \\
\hline $1-2$ & $5690(24.8)$ & $2703(22.9)$ & $2987(26.8)$ \\
\hline $3-5$ & $8050(33.0)$ & $4237(34.5)$ & $3813(31.5)$ \\
\hline $6-7$ & $4920(20.7)$ & $3049(24.5)$ & $1871(16.5)$ \\
\hline Screen-time (hour(s)/day) & & & \\
\hline 0 & $7255(31.2)$ & $3604(29.7)$ & $3651(32.8)$ \\
\hline$<1$ & $4009(15.9)$ & $1968(15.1)$ & $2041(16.7)$ \\
\hline $1-4$ & $7621(31.4)$ & $3853(31.1)$ & $3768(31.6)$ \\
\hline$\geq 4$ & $4658(21.5)$ & $2643(24.1)$ & $2015(18.9)$ \\
\hline Loneliness & & & \\
\hline Never/occasional & $15122(64.1)$ & $8082(66.8)$ & $7040(61.2)$ \\
\hline Sometimes & $5783(24.7)$ & $2698(22.6)$ & $3085(26.8)$ \\
\hline Often/always & $2638(11.2)$ & $1288(10.6)$ & $1350(12.0)$ \\
\hline Insomnia & & & \\
\hline Never/occasional & $18682(78.6)$ & $9880(81.2)$ & $8802(75.8)$ \\
\hline
\end{tabular}

Continued 


\begin{tabular}{lccc}
\hline Table 2 Continued & \multicolumn{3}{l}{} \\
\hline Characteristics & \multicolumn{1}{l}{ Total } & \multicolumn{1}{l}{ Boys } & \multicolumn{1}{c}{ Girls } \\
\hline Sometimes & $3765(16.7)$ & $1653(14.3)$ & $2112(19.3)$ \\
\hline $\begin{array}{l}\text { Often/always } \\
\text { Suicide attempt }\end{array}$ & $1096(4.7)$ & $535(4.5)$ & $561(4.9)$ \\
\hline Yes & $854(3.6)$ & $337(2.9)$ & $517(4.4)$ \\
\hline No & $22689(96.4)$ & $11731(97.1)$ & $10958(95.6)$ \\
\hline Current smoking & & & \\
\hline Yes & $1247(5.5)$ & $968(8.2)$ & $279(2.5)$ \\
\hline No & $22296(94.5)$ & $11100(91.8)$ & $11196(97.5)$ \\
\hline Fighting & $3707(15.6)$ & $2966(24.1)$ & $741(6.4)$ \\
\hline Yes & $19836(84.4)$ & $9102(75.9)$ & $10734(93.6)$ \\
\hline No & & & \\
\hline Being bullied & $3041(13.2)$ & $1872(15.7)$ & $1169(10.5)$ \\
\hline Yes & $20502(86.8)$ & $10196(84.3)$ & $10306(89.5)$ \\
\hline No & & & \\
\hline Sexual experience & $861(3.9)$ & $591(5.1)$ & $270(2.5)$ \\
\hline Yes & $22682(96.1)$ & $11477(94.9)$ & $11205(97.5)$ \\
\hline No & & & \\
\hline
\end{tabular}

Number in brackets were weighted proportion.

(27.0\% vs $18.2 \%)$, among students who ever attempted suicide ( $48.4 \%$ vs $21.8 \%$ in those without suicide attempt), among current smokers ( $73.3 \%$ vs $19.8 \%$ in non-smokers), and among students who reported ever engaging in a physical fight $(40.3 \%$ vs $19.5 \%$ in those without physical fight), ever being bullied (31.1\% vs $21.5 \%$ in those without being bullied) or having sexual experience $(59.1 \%$ vs $21.3 \%$ in those without sexual experience). There was no statistically significant difference between urban and rural areas (24.4\% vs $22.0 \%)$. In addition, the prevalence of current drinking increased with poorer academic performance, longer duration of screen-time and higher severity of loneliness or insomnia (all P values for trend $<0.0001$ ).

The prevalence of binge drinking was $9.2 \%$ (95\% CI 8.5 to 10.0 ) overall, and was $6.3 \%, 7.7 \%$ and $17.9 \%$, respectively in middle school, academic high school and vocational high school. The associations of binge drinking with sociodemographic and behavioural factors were similar to those of current drinking. The prevalence of binge drinking was higher among boys than among girls $(11.8 \%$ vs $6.5 \%)$, among students with previous suicide attempts $(31.5 \%$ vs $8.4 \%)$, among students who reported smoking cigarettes $(51.2 \%$ vs $6.8 \%)$, involvement in a physical fight $(21.5 \%$ vs $7.0 \%$ ), being bullied ( $14.1 \%$ vs $8.5 \%$ ), previous sexual experience (39.2\% vs $8.1 \%$ ), poor academic performance, longer duration of screen-time and higher severity of loneliness or insomnia ( $\mathrm{P}$ values for trend $<0.0001$ for the latter four parameters). There was no urban-rural difference in the prevalence of binge drinking $(9.8 \%$ vs $9.0 \%)$.

\section{Logistic regression analysis}

After adjusting for other variables included in the model, multivariable analysis showed that, compared with boys aged $\leq 13$ years, older boys were more likely to binge drink (table 4). Compared with boys in middle school, boys attending academic high school and vocational high school had 1.5 (OR 1.48, 95\% CI 1.15 to 1.90 ) and 2.1 (OR 2.09, 95\% CI 1.59 to 2.74) times higher probability of binge drinking. Girls attending vocational high school were 2.2 times more likely to binge drink in comparison to girls attending middle school (OR 2.18, 95\% CI 1.49 to 3.19). Boys with poor academic performance were 1.3 times more likely to binge drink in comparison to boys with excellent academic performance (OR 1.27, 95\% CI 1.03 to 1.56$)$. Compared with boys who were not physically active within the past 7 days, boys who were physically active on 6-7 days had a higher risk of binge drinking (OR 1.33, 95\% CI 1.07 to 1.66). Compared with girls with screen-time of 0 , girls with screen-time of $1-4$ hours and $>4$ hours/day were 1.6 times (OR $1.61,95 \%$ CI 1.20 to 2.17 ) and 2.6 (OR 2.59, 95\% CI 1.93 to 3.48 ) times, respectively, more likely to binge drink. Boys with screentime $>4$ hours/day had a higher risk of binge drinking in comparison to boys with screen-time of 0 (OR 1.44, $95 \%$ CI 1.16 to 1.79 ). Girls who often or always felt lonely were 1.4 times more likely to binge drink than girls who never or occasionally felt lonely (OR 1.43, 95\% CI 1.05 to 1.95 ). Boys who ever attempted suicide had 2.4 times higher odds of binge drinking than boys without a history of attempted suicide (OR 2.37, 95\% CI 1.73 to 3.25). The corresponding OR for girls was 3.4 (OR 3.36, 95\% CI 2.48 to 4.56$)$. Both boys and girls who reported smoking cigarettes within the past 30 days were 5.2 times (OR 5.21, $95 \%$ CI 4.13 to 6.58 ) and 6.7 (OR 6.68, 95\% CI 4.64 to $9.60)$ times, respectively, more likely to binge drink than their counterparts who did not smoke cigarettes. Boys who reported being involved in physical fight in previous 12 months had a 2.2 times higher risk of binge drinking than those who reported not being involved in a physical fight (OR 2.18, 95\% CI 1.81 to 2.62). The corresponding figure for girls was 2.5 (OR 2.48, 95\% CI 1.87 to 3.29). Boys who had been bullied within the previous 12 months had a 1.2 times higher risk of binge drinking than boys who had not been bullied (OR 1.23, 95\% CI 1.03 to 1.46). Both boys and girls who had sexual experience were 2.3 times (OR 2.33, 95\% CI 1.69 to 3.20) and 1.8 (OR 1.82, $95 \%$ CI 1.22 to 2.72) times, respectively, more likely to binge drink than their counterparts without sexual experience.

\section{DISCUSSION}

In this study of middle and high school students in Zhejiang, China, we examined the prevalence of current drinking and binge drinking, and identified and quantified the associations of sociodemographic and behavioural correlates of binge drinking, providing information to enable development of interventions to prevent binge drinking among this population group.

\section{Prevalence of binge drinking}

Due to different definitions of binge drinking, direct comparisons between studies are difficult. Since using a 
Open Access

Table 3 Weighted prevalence of current drinking and binge drinking by different subgroups

\begin{tabular}{|c|c|c|c|c|c|c|}
\hline \multirow[b]{2}{*}{ Characteristics } & \multicolumn{3}{|l|}{ Current drinking } & \multicolumn{3}{|l|}{ Binge drinking } \\
\hline & Prevalence $(\%)^{\star}$ & $\chi^{2}$ & $P$ value & Prevalence $(\%)^{*}$ & $\chi^{2}$ & $P$ value \\
\hline Sex & & $93.65 \dagger$ & $<0.0001$ & & $80.46 \dagger$ & $<0.0001$ \\
\hline Boys & $27.0(25.6-28.5)$ & & & $11.8(10.8-12.9)$ & & \\
\hline Girls & $18.2(16.8-19.6)$ & & & $6.5(5.6-7.3)$ & & \\
\hline Area & & $2.38 \dagger$ & 0.12 & & $0.62 \dagger$ & 0.4314 \\
\hline Urban & $24.4(21.9-26.9)$ & & & $9.8(8.2-11.4)$ & & \\
\hline Rural & $22.0(20.5-23.5)$ & & & $9.0(8.0-10.0)$ & & \\
\hline Types of school & & $319.93 \dagger$ & $<0.0001$ & & $278.29 \dagger$ & $<0.0001$ \\
\hline Middle school & $17.5(16.2-18.8)$ & & & $6.3(5.6-7.0)$ & & \\
\hline Academic high school & $22.1(20.4-23.8)$ & & & $7.7(6.8-8.7)$ & & \\
\hline Vocational high school & $35.9(33.7-38.0)$ & & & 17.9 (15.9-20.0) & & \\
\hline Academic performance & & $68.9 \ddagger$ & $<0.0001$ & & $51.7 \ddagger$ & $<0.0001$ \\
\hline Excellent & $18.2(16.4-20.0)$ & & & $6.9(5.7-8.1)$ & & \\
\hline Middle & $21.6(20.2-22.9)$ & & & $8.5(7.6-9.3)$ & & \\
\hline Poor & $28.8(26.9-30.6)$ & & & $12.7(11.5-13.8)$ & & \\
\hline Physical activity (days/week) & & $1.10 \ddagger$ & 0.2977 & & $2.0 \ddagger$ & 0.1555 \\
\hline 0 & $23.2(21.6-24.8)$ & & & $9.7(8.7-10.8)$ & & \\
\hline $1-2$ & $22.0(20.5-23.5)$ & & & $8.5(7.4-9.5)$ & & \\
\hline $3-5$ & $21.7(20.1-23.2)$ & & & $8.3(7.3-9.3)$ & & \\
\hline $6-7$ & $25.0(23.0-26.9)$ & & & $11.2(9.9-12.5)$ & & \\
\hline Screen-time (hour(s)/day) & & $330.9 \ddagger$ & $<0.0001$ & & $259.6 \ddagger$ & $<0.0001$ \\
\hline 0 & $16.1(14.8-17.3)$ & & & $5.5(4.8-6.3)$ & & \\
\hline$<1$ & $16.8(15.3-18.3)$ & & & $5.5(4.7-6.4)$ & & \\
\hline $1-4$ & $23.3(21.8-24.7)$ & & & $8.9(7.8-9.9)$ & & \\
\hline$\geq 4$ & $36.1(34.0-38.1)$ & & & 17.9 (16.3-19.6) & & \\
\hline Loneliness & & $149.6 \ddagger$ & $<0.0001$ & & $113.9 \ddagger$ & $<0.0001$ \\
\hline Never/occasional & $19.6(18.4-20.7)$ & & & $7.5(6.8-8.2)$ & & \\
\hline Sometimes & $26.2(24.4-27.9)$ & & & $10.4(9.4-11.5)$ & & \\
\hline Often/always & $33.5(31.4-35.6)$ & & & 16.5 (14.7-18.3) & & \\
\hline Insomnia & & $177.2 \ddagger$ & $<0.0001$ & & 205.3‡ & $<0.0001$ \\
\hline Never/occasional & 20.4 (19.3-21.5) & & & $7.7(7.0-8.3)$ & & \\
\hline Sometimes & $29.3(27.3-31.2)$ & & & $13.0(11.6-14.5)$ & & \\
\hline Often/always & $39.2(35.8-42.5)$ & & & $22.7(19.9-25.5)$ & & \\
\hline Suicide attempt & & $204.61 \dagger$ & $<0.0001$ & & $288.99 \dagger$ & $<0.0001$ \\
\hline Yes & $48.4(44.2-52.6)$ & & & $31.5(27.4-35.6)$ & & \\
\hline No & $21.8(20.6-23.0)$ & & & $8.4(7.7-9.2)$ & & \\
\hline Current smoking & & $7335.31 \dagger$ & $<0.0001$ & & 3720.33† & $<0.0001$ \\
\hline Yes & $73.3(70.5-76.0)$ & & & $51.2(47.2-55.2)$ & & \\
\hline No & 19.8 (18.9-20.8) & & & $6.8(6.3-7.4)$ & & \\
\hline Fighting & & $257.16 \dagger$ & $<0.0001$ & & $307.89 \dagger$ & $<0.0001$ \\
\hline Yes & $40.3(37.2-43.4)$ & & & 21.5 (19.1-23.9) & & \\
\hline No & 19.5 (18.5-20.6) & & & $7.0(6.3-7.6)$ & & \\
\hline Being bullied & & 49.13† & $<0.0001$ & & $38.81 \dagger$ & $<0.0001$ \\
\hline Yes & $31.1(28.1-34.1)$ & & & $14.1(12.0-16.2)$ & & \\
\hline No & $21.5(20.4-22.6)$ & & & $8.5(7.8-9.2)$ & & \\
\hline Sexual experience & & $526.80 \dagger$ & $<0.0001$ & & $500.40 \dagger$ & $<0.0001$ \\
\hline Yes & $59.1(54.5-63.6)$ & & & $39.2(33.8-44.5)$ & & \\
\hline No & $21.3(20.2-22.4)$ & & & $8.1(7.4-8.7)$ & & \\
\hline
\end{tabular}

*Based on the weighted data.

†Rao-Scott $\chi^{2}$.

$\ddagger$ Trend for $\chi^{2}$. 
Table 4 Crude and adjusted OR of factors associated with binge drinking among adolescents in China

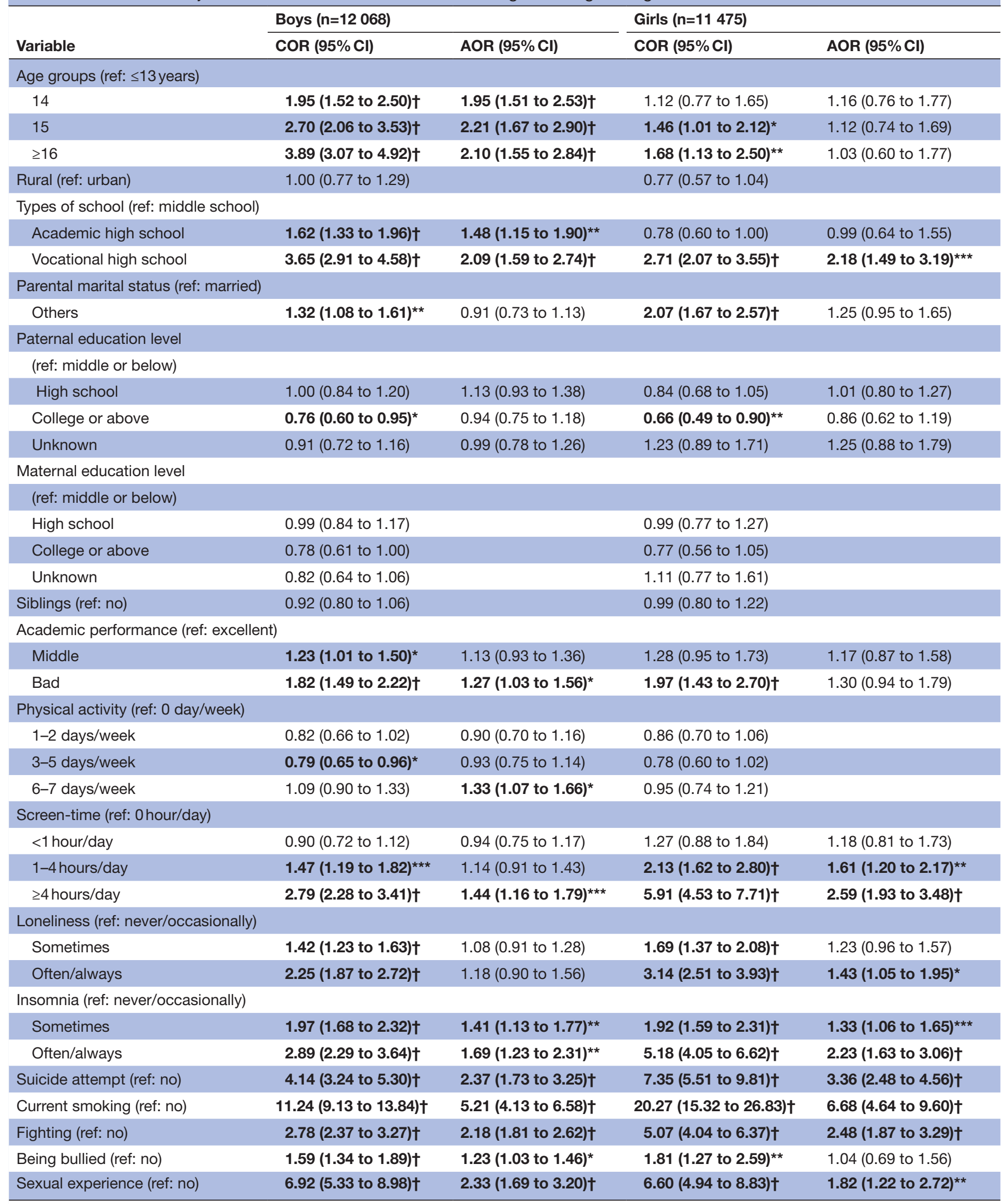

Bold numbers represent significant results.

AOR is adjusted for all other covariates in the model.

${ }^{*} \mathrm{P}<0.05,{ }^{* \star} \mathrm{P}<0.01,{ }^{* \star *} \mathrm{P}<0.001,+\mathrm{P}<0.0001$.

COR, crude OR; AOR, adjusted OR. 
5-drink measure for high school students in 1975, most national surveys have defined binge drinking as 5 or more drinks among both women and men. ${ }^{12} 17$ A new gender-specific measure of $\geq 4 / 5$ drinks for women/ men has been used by Harvard School to reflect gender differences in the risk of alcohol-related harms. ${ }^{30-32}$ The use of these gender-specific thresholds is also justified by women's generally smaller stature, and physiological differences between men and women affecting the absorption and distribution of alcohol. ${ }^{33}$ Other studies have also used a 6-drink measure for both women and men. ${ }^{18}$ In the present study, we adopted the definition of $\geq 4 / 5$ drinks for women/men and found an overall prevalence of binge drink in Zhejiang of 9.2\%, which was higher than previously reported in Hong Kong $(7.1 \%) .{ }^{15}$ The higher prevalence among boys than girls was consistent with results from other studies, ${ }^{15} 1834$ but differs from a Korean study, in which no sex difference was observed. ${ }^{14}$ The highest prevalence of binge drinking in the current study was among students attending vocational high schools. A possible explanation for this was that, compared with middle school and academic high school students, vocational high school students are likely to enter employment immediately following graduation, for which social communication and interaction, possibly associated with alcohol consumption, may be considered important. ${ }^{17}$ In subgroup analyses, the highest prevalence of binge drinking was among current drinkers (51.2\%), students with sexual experience $(39.2 \%)$ and students who had a history of a previous suicide attempt $(31.5 \%)$. This suggests that such students should be identified as target populations for interventions to prevent and address binge drinking.

\section{Association of demographic factors of binge drinking}

No association was found between parental educational levels and binge drinking in our study. In a systematic review, including 20 studies from 10 countries or areas, parental socioeconomic status, defined as the educational level, income or occupation, was weakly positively associated with binge drinking in low-income and middle-income countries. However, no such association was not found in high-income countries. ${ }^{35} \mathrm{~A}$ previous study reported that non-intact family structure was associated with alcohol drinking among adolescents due to low family attachment or insufficient parent-child communication. ${ }^{24}{ }^{25}$ However, no such association was found in our study, which may reflect somewhat cultural differences in parental attitudes to alcohol consumption. van den Eijnden $e t a \vec{l}^{6}$ found that adolescents were less likely to drink under strict alcohol-specific rules at homes despite non-intact families.

\section{Association of behavioural factors of binge drinking}

A cohort study, including 89 university students who were followed up for 2 years, found persistent binge drinking was associated with verbal memory and monitoring difficulties. ${ }^{37}$ This might be a possible reason for the positive association we observed between poor academic performance and binge drinking (ie, binge drinking may cause poor academic performance). Several earlier studies have also documented poorer performance among binge drinking students on neuropsychological tasks assessing inhibitory control, cognitive interference, sustained attention, verbal working memory and episodic declarative memory, ${ }^{38-41}$ functions which are known to be supported by prefrontal and/or hippocampal regions, and these may also explain associations between poor academic performance and binge drinking.

Buscemi $e t a l^{42}$ found a positive relationship between moderate physical activity and alcohol use among males, but not females. Another study documented a positive relationship between vigorous physical activity and alcohol use, which was stronger at younger ages. ${ }^{43}$ Our study showed that boys who were physically active were 1.3 times more likely to binge drink than boys who were not physically active. It is unclear whether physical activity leads to increased odds of binge drink or whether the converse is true (ie, binge drinking causes increased physical activity). One possible hypothesis might be that more physically active boys may binge drink as a means of relaxation. Further prospective studies are warranted to ascertain the likely direction of association between physical activity and binge drinking, and underlying mechanisms.

In our study, nearly one in five students reported $>4$ hours screen-time per day. Previous studies have mainly focused on television watching as a potential risk factor for various diseases. ${ }^{44-47}$ However, the exponential growth of electronic screen products suggests that focusing only on television viewing might underestimate screen-time. ${ }^{48}$ To the best of our knowledge, this is the first study to examine the association between screentime and adolescent binge drinking, finding a positive association between duration of exposure to electronic screen products and odds of binge drinking.

Alcohol drinking can damage neurons, decrease neurogenesis, and cause cognitive and affective dysfunction, especially among adolescents. ${ }^{49}$ Laboratory evidence has shown that decreased neurogenesis results in depression-like behaviours in rats. ${ }^{50}$ The relationship of alcohol use with mental health has been suggested to be bidirectional. Rohde $e t a \tilde{l}^{2}$ reported that the onset of psychiatric disorder preceded the onset of alcoholism, while Berglund and Ojehagen ${ }^{53}$ reported that depression followed alcoholism. However, although a previous study has indicated that substance use might be a means of self-medication and of alleviating the negative feelings that emanate from being lonely, ${ }^{54}$ binge drinking has been shown to be ineffective in improving mental health. ${ }^{55}$ In our study, loneliness was positively associated with adolescent binge drinking, but this association was found only among girls, consistent with findings among Arkhangelsk adolescents. ${ }^{56}$ Furthermore, Huang et $a p^{5}$ reported that alcohol drinking was significantly associated with emotional symptoms among girls only. Our findings suggest that preventive strategies against binge 
drinking for female adolescents should include mental health consultation.

As demonstrated in our study, with higher levels of insomnia, the odds of adolescent binge drinking was higher. A previous study by Popovici and French, ${ }^{58}$ including 14089 participants, found that binge drinking was positively associated with sleep problems (having trouble falling asleep or staying asleep), independent of psychiatric conditions. There was a dose-response relationship between sleep problems and frequency of binge drinking, consistent with our study. In addition, Sharma et a $\tilde{l}^{\tilde{9}}$ found that binge drinking could reverse sleep-wake cycle in rats and produce symptoms of insomnia, which could provide some explanation for the association between insomnia and binge drinking among students in the current study.

Alcohol drinking is a well-established risk factor for suicide attempts ${ }^{6061}$ and acute intoxication may be a stronger risk factor than chronic alcohol use, ${ }^{60}$ suggesting that binge drinking, which may produce rapid intoxication, may elevate the risk of suicide. In our study, prior suicide attempt was positively associated with binge drinking. Consistent with previous studies, binge drinking was related to the use of cigarettes. ${ }^{62}{ }^{63}$ In our study, current smoking had the strongest association with the odds of binge drinking, with over 5 and 6 times higher odds of binge drinking among current smoking boys and girls, respectively. Adolescents who drink alcohol are more likely to be involved in interpersonal conflicts and violence. ${ }^{23}$ Our findings that both fighting and being bullied were positively related to adolescent binge drinking highlights the need for adolescent violence prevention programmes focusing on the reduction of alcohol abuse. We found a positive association between binge drinking and sexual experience, which was consistent with an earlier study. ${ }^{23}$ Lewis $e t a{ }^{64}$ reported that alcohol may facilitate formation of intimate relationship. In addition, a previous study reported that binge drinking among adolescents was associated with higher rates of unwanted pregnancy, sexually transmitted infections and infertility. ${ }^{8}$

\section{Limitations}

Our study had several limitations. First, the a cross-sectional study design prevents establishment of the causal relationships between sociodemographic and behavioural factors and binge drinking. Second, all data were self-reported by students, and self-reported alcohol consumption may be susceptible to recall and social desirability biases. Third, only students attending schools participated in the survey. Students who had been expelled or suspended from school, or who stopped attending, may be more likely to binge drink, and the overall prevalence of binge drinking in our current study might therefore represent an underestimate of the true prevalence.

\section{CONCLUSIONS}

Despite these limitations, our study identified correlates of binge drinking among middle and high school students in Zhejiang and quantified the strength of these associations, providing insight to inform binge drinking prevention strategies. Efforts to prevent binge drinking may need to address a cluster of correlating factors, including cigarette smoking, excessive screentime, suicide attempt, fighting, being bullied, loneliness, insomnia and sexual behaviour. The presented findings provide evidence to assist healthcare providers in identifying students at high risk of binge drinking, which will aid in the planning of prevention and intervention measures for at-risk students.

Acknowledgements The authors would like to thank all the students, parents, teachers and local officials for their participation, assistance and cooperation.

Contributors HW designed the study, and collected and analysed the data with MY. $\mathrm{JZ}$ and $\mathrm{RH}$ were involved in data interpretation. $\mathrm{HD}$ and BF took part in data analysis and revised the manuscript. MW was involved in data collection. All the authors have read and approved the final submitted version.

Funding The work was supported by grant (2016YFC0900502) from National Key Research and Development Program of China.

Competing interests None declared.

Patient consent Detail has been removed from this case description/these case descriptions to ensure anonymity. The editors and reviewers have seen the detailed information available and are satisfied that the information backs up the case the authors are making.

Ethics approval Ethics Committee of Zhejiang Provincial Centre for Disease Control and Prevention.

Provenance and peer review Not commissioned; externally peer reviewed. Data sharing statement No additional data are available.

Open Access This is an Open Access article distributed in accordance with the terms of the Creative Commons Attribution (CC BY 4.0) license, which permits others to distribute, remix, adapt and build upon this work, for commercial use, provided the original work is properly cited. See: http://creativecommons.org/ licenses/by/4.0/

(c) Article author(s) (or their employer(s) unless otherwise stated in the text of the article) 2018. All rights reserved. No commercial use is permitted unless otherwise expressly granted.

\section{REFERENCES}

1. Rehm J, Mathers C, Popova S, et al. Global burden of disease and injury and economic cost attributable to alcohol use and alcohol-use disorders. Lancet 2009;373:2223-33.

2. GBD 2016 Risk Factors Collaborators. Global, regional, and national comparative risk assessment of 84 behavioural, environmental and occupational, and metabolic risks or clusters of risks, 1990-2016: a systematic analysis for the Global Burden of Disease Study 2016. Lancet 2017;390:1345-422.

3. Bingham CR, Shope JT, Parow JE, et al. Crash types: markers of increased risk of alcohol-involved crashes among teen drivers. $J$ Stud Alcohol Drugs 2009;70:528-35.

4. Scott KD, Schafer J, Greenfield TK. The role of alcohol in physical assault perpetration and victimization. J Stud Alcohol 1999;60:528-36.

5. Foran HM, O'Leary KD. Alcohol and intimate partner violence: a meta-analytic review. Clin Psychol Rev 2008;28:1222-34.

6. Katon W, Richardson L, Russo J, et al. Depressive symptoms in adolescence: the association with multiple health risk behaviors. Gen Hosp Psychiatry 2010;32:233-9.

7. Marmorstein NR. Longitudinal associations between alcohol problems and depressive symptoms: early adolescence through early adulthood. Alcohol Clin Exp Res 2009;33:49-59.

8. Stolle M, Sack PM, Thomasius R. Binge drinking in childhood and adolescence: epidemiology, consequences, and interventions. Dtsch Arztebl Int 2009;106:323-8.

9. Degenhardt L, O'Loughlin C, Swift W, et al. The persistence of adolescent binge drinking into adulthood: findings from a 15-year prospective cohort study. BMJ Open 2013;3:e003015. 
10. Viner RM, Taylor B. Adult outcomes of binge drinking in adolescence: findings from a UK national birth cohort. J Epidemiol Community Health 2007;61:902-7.

11. Kim JH, Lee S, Chow J, et al. Prevalence and the factors associated with binge drinking, alcohol abuse, and alcohol dependence: a population-based study of Chinese adults in Hong Kong. Alcohol Alcohol 2008;43:360-70.

12. The ESPAD Group. ESPAD report 2015. Result from the European School Survey project on alcohol and other drugs. Lisbon, 2016.

13. Esser MB, Clayton H, Demissie Z, et al. Current and binge drinking among high school students - United States, 1991-2015. MMWR Morb Mortal Wkly Rep 2017;66:474-8.

14. Chung SS, Joung KH. Risk factors of heavy episodic drinking among Korean adolescents. J Psychiatr Ment Health Nurs 2013;20:665-71.

15. Huang R, Ho SY, Wang MP, et al. Sociodemographic risk factors of alcohol drinking in Hong Kong adolescents. J Epidemiol Community Health 2016;70:374-9.

16. Qian L, Yi HG, Tian BC, et al. [Alcohol consumption and drug use among middle school students aged 13-15 in 4 cities of China]. Zhonghua Liu Xing Bing Xue Za Zhi 2006;27:483-7.

17. Xing $Y$, Ji C, Zhang L. Relationship of binge drinking and other health-compromising behaviors among urban adolescents in China. $J$ Adolesc Health 2006;39:495-500.

18. Lu S, Du S, Hu X, et al. Drinking patterns and the association between socio-demographic factors and adolescents' alcohol use in three metropolises in China. Int J Environ Res Public Health 2015;12:2037-53.

19. Au WM, Ho SY, Wang MP, et al. Correlates of pro-drinking practices in drinking parents of adolescents in Hong Kong. PLoS One 2015;10:e0119554.

20. Wang S, Newman IM, Shell DF. Cultural Orientation and Its Associations with Alcohol Use by University Students in China. PLoS One 2016;11:e0165858.

21. Newman J, Xue J, Fang X. Alcohol use and its risk factors among high school students in Beijing. Chin J Sch Health 2004;25:385-6.

22. Zuo J, Wang H, Zhou N. Investigation on the the drinking state and the influencing factors in middle school students in Wuhan City. Chin Med Soc 2001;14:10-12.

23. Miller JW, Naimi TS, Brewer RD, et al. Binge drinking and associated health risk behaviors among high school students. Pediatrics 2007;119:76-85.

24. Sokol-Katz J, Dunham R, Zimmerman R. Family structure versus parental attachment in controlling adolescent deviant behavior: a social control model. Adolescence 1997;32:199-215.

25. Mak KK, Ho SY, Thomas GN, et al. Family structure, parent-child conversation time and substance use among Chinese adolescents. BMC Public Health 2010;10:503.

26. Centers for Disease Control and Prevention. State and local youth risk behavior survey. $2017 \mathrm{https}: / / w w w . c d c . g o v / h e a l t h y y o u t h / d a t a /$ yrbs/questionnaires.htm (accessed 21 Nov 2017).

27. World Health Organization. Global school-based students health survey (GSHS). 2015 http://www.who.int/ncds/surveillance/gshs/ nepal/en/ (accessed 21 Nov 2017).

28. Newsletter N. NIAAA council approves definition of binge drinking, 2004.

29. Pengpid S, Peltzer K. Alcohol use and associated factors among adolescent students in Thailand. West Indian Med $\mathrm{J}$ 2012;61:890-6.

30. Wechsler H, Austin SB. Binge drinking: the five/four measure. J Stud Alcohol 1998;59:122-4.

31. Wechsler H, Dowdall GW, Davenport A, et al. A gender-specific measure of binge drinking among college students. Am J Public Health 1995;85:982-5.

32. Wechsler $\mathrm{H}$, Nelson TF. Binge drinking and the American college student: what's five drinks? Psychol Addict Behav 2001;15:287-91.

33. Baraona E, Abittan CS, Dohmen K, et al. Gender differences in pharmacokinetics of alcohol. Alcohol Clin Exp Res 2001;25:502-7.

34. Tavolacci MP, Boerg E, Richard L, et al. Prevalence of binge drinking and associated behaviours among 3286 college students in France. BMC Public Health 2016;16:178.

35. Kwok KH, Yuan SN. Parental socioeconomic status and binge drinking in adolescents: a systematic review. Am J Addict 2016:610-9.

36. van den Eijnden $\mathrm{R}$, Mheen $\mathrm{D}$, Vet $\mathrm{R}$, et al. Alcohol-specific parenting and adolescents' alcohol-related problems: the interacting role of alcohol availability at home and parental rules. J Stud Alcohol Drugs 2011;72:408-17.

37. Mota N, Parada M, Crego A, et al. Binge drinking trajectory and neuropsychological functioning among university students: a longitudinal study. Drug Alcohol Depend 2013;133:108-14.
38. Heffernan T, Clark R, Bartholomew J, et al. Does binge drinking in teenagers affect their everyday prospective memory? Drug Alcohol Depend 2010;109:73-8.

39. Ehlers CL, Phillips E, Finnerman G, et al. P3 components and adolescent binge drinking in Southwest California Indians. Neurotoxicol Teratol 2007;29:153-63.

40. García-Moreno LM, Expósito J, Sanhueza C, et al. [Prefrontal activity and weekend alcoholism in the young]. Adicciones 2008;20:271-9.

41. Johnson CA, Xiao L, Palmer P, et al. Affective decision-making deficits, linked to a dysfunctional ventromedial prefrontal cortex, revealed in 10th grade Chinese adolescent binge drinkers. Neuropsychologia 2008;46:714-26.

42. Buscemi J, Martens MP, Murphy JG, et al. Moderators of the relationship between physical activity and alcohol consumption in college students. J Am Coll Health 2011;59:503-9.

43. Lisha NE, Martens M, Leventhal AM. Age and gender as moderators of the relationship between physical activity and alcohol use. Addict Behav 2011;36:933-6.

44. Alghadir AH, Gabr SA, lqbal ZA, et al. diet and body mass index of school children in Saudi Arabia. Pediatr Int 2016;58:290-4.

45. Al-Ghamdi SH. The association between watching television and obesity in children of school-age in Saudi Arabia. J Family Community Med 2013;20:83-9.

46. Mamun AA, O'Callaghan MJ, Williams $G$, et al. Television watching from adolescence to adulthood and its association with BMI, waist circumference, waist-to-hip ratio and obesity: a longitudinal study. Public Health Nutr 2013;16:54-64.

47. Mekary RA, Lucas M, Pan A, et al. Isotemporal substitution analysis for physical activity, television watching, and risk of depression. Am J Epidemiol 2013;178:474-83.

48. Jiang XX, Hardy LL, Ding D, et al. Recreational screen-time among Chinese adolescents: a cross-sectional study. J Epidemiol 2014;24:397-403.

49. Guerri C, Pascual M. Mechanisms involved in the neurotoxic, cognitive, and neurobehavioral effects of alcohol consumption during adolescence. Alcohol 2010;44:15-26.

50. Santarelli L, Saxe M, Gross C, et al. Requirement of hippocampal neurogenesis for the behavioral effects of antidepressants. Science 2003;301:805-9.

51. Malberg JE, Eisch AJ, Nestler EJ, et al. Chronic antidepressant treatment increases neurogenesis in adult rat hippocampus. $J$ Neurosci 2000;20:9104-10.

52. Rohde P, Lewinsohn PM, Seeley JR. Psychiatric comorbidity with problematic alcohol use in high school students. J Am Acad Child Adolesc Psychiatry 1996;35:101-9.

53. Berglund $M$, Ojehagen $A$. The influence of alcohol drinking and alcohol use disorders on psychiatric disorders and suicidal behavior. Alcohol Clin Exp Res 1998:22:333s-45.

54. Page RM, Dennis M, Lindsay GB, et al. Psychosocial distress and substance use among adolescents in four countries: Philippines, China, Chile, and Namibia. Youth \& Society 2011;43:900-30.

55. Kim JH, Chan KW, Chow JK, et al. University binge drinking patterns and changes in patterns of alcohol consumption among chinese undergraduates in a Hong Kong university. J Am Coll Health 2009;58:255-65.

56. Stickley A, Koyanagi A, Koposov R, et al. Loneliness and health risk behaviours among Russian and U.S. adolescents: a cross-sectional study. BMC Public Health 2014;14:366.

57. Huang R, Ho SY, Wang MP, et al. Reported alcohol drinking and mental health problems in Hong Kong Chinese adolescents. Drug Alcohol Depend 2016;164:47-54.

58. Popovici I, French MT. Binge drinking and sleep problems among young adults. Drug Alcohol Depend 2013;132:207-15.

59. Sharma R, Bradshaw K, Sahota P, et al. Acute binge alcohol administration reverses sleep-wake cycle in Sprague Dawley rats. Alcohol Clin Exp Res 2014;38:1941-6.

60. Cherpitel CJ, Borges GL, Wilcox HC. Acute alcohol use and suicidal behavior: a review of the literature. Alcohol Clin Exp Res 2004;28:18S-28.

61. Kaplan MS, Giesbrecht N, Caetano R, et al. Acute alcohol consumption as a contributing factor to suicidal behavior. $A m \mathrm{~J}$ Public Health 2013;103:e2-e3.

62. Hale D, Viner R. Trends in the prevalence of multiple substance use in adolescents in England, 1998-2009. J Public Health 2013;35:367-74.

63. Stickley A, Koyanagi A, Koposov R, et al. Binge drinking among adolescents in Russia: prevalence, risk and protective factors. Addict Behav 2013;38:1988-95.

64. Lewis MA, Granato H, Blayney JA, et al. Predictors of hooking up sexual behaviors and emotional reactions among U.S. college students. Arch Sex Behav 2012;41:1219-29. 